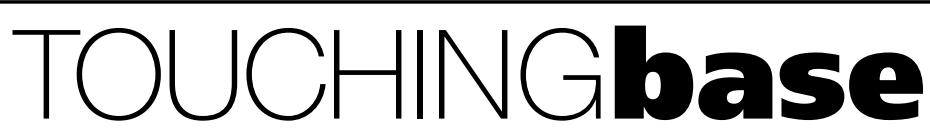

Don't drink and ... smell

A mouse knockout of a gene in the Notch signaling pathway is hypersensitive to ethanol and unable to discriminate among odors, according to a paper published in the 31 July online edition of the Proceedings of the National Academy of Sciences. Youlin Ruan and colleagues (University of California, San Francisco) cloned a mouse homolog of Drosophila neuralized (neu) - a gene in the Notch receptor-mediated signaling pathway that specifies sensory organ and photoreceptor cell fates in the fly. Mice deficient for the gene, $m$-neu1, are viable, and their behavior, including learning and memory, seems normal. However, the mice are unable to distinguish a specific odor associated with an adverse stimulus. Whereas the wildtype mice learned to avoid the odor, the mutant mice were unable to recognize it. In addition, when exposed to ethanol the mutants had more trouble with their motor coordination than did the wildtype mice. Thus, the authors conclude, $m$-neu1 is important for the proper formation or function of the nervous system structures critical for odor discrimination and ethanol sensitivity.

\section{In a pig's eye}

With the debate about genetically modified (GM) foods being eclipsed by the human cloning issue, can it be that a significant development has been overlooked? Much of the debate centers on a few GM plants that have been commonplace (although underrecognized) in the American and Chinese diets for many years. But no one has been eating genetically modified meat ... until now. New Scientist reports the accidental consumption of transgenic sausages. As part of a research program on eye function, researchers at the University of Florida created transgenic pigs carrying the human rhodopsin gene. Three of the dead experimental animals were apparently stolen and passed on to an unsuspecting butcher who turned at least some of the ill-gotten gains into sausages. It is reported that Helen Griffin ate approximately five pounds (a little over $2 \mathrm{~kg}$ ) of the hi-tech sausage and declared they "tasted very good". Surely the trial and result to finally silence all critics of GM organisms!

\section{- Celera wins NIH award}

The National Institute of Allergy and Infectious Diseases (NIAID) at the National Institutes of Health $(\mathrm{NIH})$ will award $\$ 9$ million to the Celera Genomics Group to determine the sequence of Anopheles gambiae, the mosquito that transmits the malaria parasite, Plasmodium falciparum. According to a spokesperson at the NIAID, Celera's technology gave them the edge in the competition for the award. One of the requirements of the award is that the information be made freely available to the scientific community. Malaria parasites have a complex life cycle that includes interactions with both human and mosquito hosts. With the human genome already sequenced and the genome of $P$. falciparum soon to be sequenced, the sequencing of the $A$. gambiae genome will complete the picture. Celera will sequence and carry out the initial annotation of the mosquito genome, a project that the company expects to finish by next spring. The project builds on two earlier sequencing awards that the NIAID made to Frank Collins at the University of Notre Dame and is part of an international Anopheles sequencing consortium that includes the Pasteur Institute's sequencing center (Genoscope), the European Molecular Biology Laboratory and others.

\section{Whitehead gets ready to tango}

Next month, Susan Lindquist, Howard Hughes Medical Institute investigator and professor at the University of Chicago, will assume a new post as director of the Whitehead Institute for Biomedical Research. Lindquist's predecessor, Gerald Fink, steps down as director of the esteemed research institute after serving for ten years. Lindquist is well known for seminal work on heat shock proteins in yeast and Drosophila and on the conformational changes that regulate the replication of prion proteins. What many people may not know is that, according to the Whitehead's press office, Lindquist is also an accomplished ballroom dancer who loves the Argentine tango best.

\title{
Quoting cloning
}

Excitement and concern mount over the issue of human cloning, following the barefaced announcement of Severino Antinori and Panayiotis Zavos that, by November of this year, they will start a cloning program to help infertile couples. With this upping of the ante the debate has spread from tabloid front page to the hallowed halls of the U.S. National Academy of Sciences. Few in number, proponents argue that the technique (involving the transfer of the full genetic complement of one individual to an enucleated egg which is then stimulated to start dividing) is now ready for human application. The majority argue that, ethics aside, the technique has not been proven safe. The issue is receiving a full (if somewhat breathless) public airing, with opportunities for all voices to be heard. Here are some of them:

"At present there is no way to predict whether a given clone will develop into a normal or abnormal individual." Rudolf Jaenish (M.I.T)

"Unless we do it with the human, we'll never have the human data to discuss..."

Panayiotis Zavos (fertility expert)

"We are seeing a great range of abnormalities...we should expect a similar outcome if people attempt to produce a cloned human." Ian Wilmut (Roslin Institute)

"The demand is huge... and this will be done." "I do believe that we have everything we need to proceed." Brigitte Boisselier (Clonaid)

"The technique remains extremely inefficient...practice makes perfect, but is it ethical to practice [on people]?" Alan Colman (PPL Therapeutics)

"We definitely will pursue therapeutic cloning and [will] try to sway public opinion that this is the future of medicine." Jose Cibellie (Advanced Cell Technology)

"It is manufacturing human beings in a new and exploitative way." Jack Scarisbrick (pro-life campaigner)

"This is a part of human evolution." Zavos

"A Pandora's box would be opened."

Patrick Mahoney (Christian Defense Coalition)

"Copying children for reasons other than treating sterility is Nazi madness."

Cardinal Joseph Ratzinger 